"Do your part: Stay apart": Collective intentionality and collective (in)action in US governor's COVID-19 press conferences

\author{
Z.M. Kirgil , A. Voyer
}

PII:

S0304-422X(22)00030-4

DOI: https://doi.org/10.1016/j.poetic.2022.101668

Reference: POETIC 101668

To appear in:

Poetics

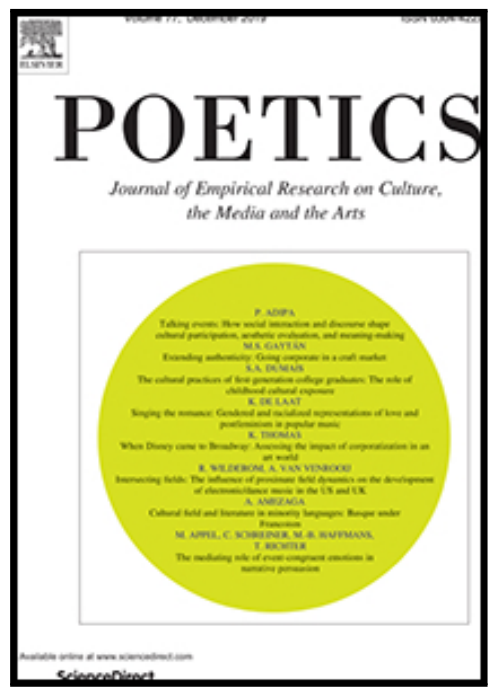

Received date:

30 June 2021

Revised date:

27 January 2022

Accepted date:

6 March 2022

Please cite this article as: Z.M. Kirgil , A. Voyer, "Do your part: Stay apart": Collective intentionality and collective (in)action in US governor's COVID-19 press conferences, Poetics (2022), doi: https://doi.org/10.1016/j.poetic.2022.101668

This is a PDF file of an article that has undergone enhancements after acceptance, such as the addition of a cover page and metadata, and formatting for readability, but it is not yet the definitive version of record. This version will undergo additional copyediting, typesetting and review before it is published in its final form, but we are providing this version to give early visibility of the article. Please note that, during the production process, errors may be discovered which could affect the content, and all legal disclaimers that apply to the journal pertain.

(C) 2022 The Author(s). Published by Elsevier B.V.

This is an open access article under the CC BY-NC-ND license

(http://creativecommons.org/licenses/by-nc-nd/4.0/) 


\section{Highlights}

- We develop a new measurement of collective intentionality for text analysis.

- US political leaders mobilize collective intentionality during the COVID-19 pandemic to foster prosocial action.

- In democratic administrations, collective intentionality is linked to individuals' agency and actions.

- In republican administrations individuals' contributions are downplayed compared to work and state-level action. 


\title{
"Do your part: Stay apart": Collective intentionality and collective (in)action in US governor's COVID-19 press conferences
}

\author{
Z.M. Kirgil" melis.kirgil@ sociology.su.se, A. Voyer
}

Stockholm University, Sweden

"Correspondence: Zeynep Melis Kirgil, Department of Sociology, Faculty of Social Sciences, Stockholm University, Universitetsvägen 10 B, 10691 Stockholm, Sweden

Abstract

This mixed-methods study examines how political leaders mobilize collective intentionality during the COVID19 pandemic in nine US States, and how collective intentionality differs across republican and democratic administrations. The results of our computational and qualitative analyses show that i) political leaders establish collective intentionality by emphasizing unity, vulnerability, action, and community boundaries; ii) political leaders' call to collective action clashes with the inaction required by health guidelines; iii) social inequalities received little attention across all states compared to other themes; and iv) collective intentionality in democratic administrations is linked to individuals' agency and actions, suggesting a bottom-up approach. Conversely, in republican administrations individuals' contributions are downplayed compared to work and state-level action, indicating a top-down approach. This study demonstrates the theoretical and empirical value of collective intentionality in sociological research, and contributes to a better understanding of leadership and prosociality in times of crisis.

\section{Keywords}

Collective Intentionality, Leadership, Democrat, Republican, COVID-19.

\section{Introduction}

This article examines how political leaders utilize collective intentionality, a crucial mechanism of cooperation, to emphasize unity and mobilize prosocial action in public addresses. Collective intentionality describes peoples' ability to engage in collective reasoning and action (Tuomela 2013). In times of crisis, people look to their leaders for guidance in interpreting emergencies and determining how to behave (Crayne and Medeiros 2020). The role of the state during such times includes the provision of necessary aid and the development of responsive policy, but it also extends to the symbolic performance of 
sympathy, compassion and resolve in shouldering the burden of the crisis ( $\mathrm{Xu}$ and Bernau 2021). Changes in the environment, such as the COVID pandemic, evoke the need for sensemaking (Medeiros et al. 2022; Weick et al. 2005), and as representatives of the government, political leaders are thus expected to make sense of the crisis situation, manage responses, and take initiatives (Ansell, Boin, and 't Hart 2014). Studies show an empirical link between crisis situations (Halverson, Murphy, and Riggio, 2004) or crisis perceptions (Bligh, Kohles, and Pillai 2005) and leader's perceived charisma, as well as between leadership styles and people's beliefs and perceptions (Lyons and Schneider 2009). Due to the threatening nature of crises, political actors receive a floodlit stage for their crisis management ('t Hart and Boin 2001) and are required to take urgent action (Zhang, Jia, and $\mathrm{Gu}$ 2012). Previous research has shown that in crisis situations an increasing sense of solidarity or conflict can arise (Carroll et al. 2006; Collins 2004; Turkel 2002; Ryan and Hawdon 2008). Moreover, people tend to share a collective sense of pride and togetherness with their community in times of crisis (Ryan and Hawdon 2008: 47). To foster compliance and prosocial behavior from "the citizen audience" (Wrenn 2012), political leaders nurture these collective elements in public discourse. Recent findings suggest that people with higher collective intentionality show higher cooperation (Kirgil, Wittek and Postmes 2021; Titlestad 2019).

It is not a stretch to suggest that the COVID-19 pandemic was a crisis calling for the performance of leadership. In the United States, the lack of coordinated national response put State and local officials at the forefront of COVID-19 leadership. In an effort to convey information and direct the response to the health crisis, many of these public figures used press conferences as a key method for crisis communication (Villegas 2020; see also Garnett and Kouzman 2007). A political press conference is a "ritualized event, with the objective of projecting a united front on crucial global political issues" (Bhatia 2006: 176). Conferences 
can take a variety of forms based on their objective - for example, press conferences may be single-party and campaign-style media events, or they may multi-party press conferences including two or more international leaders at the conclusion of diplomatic talks (Bhatia, 2006; Eshbaugh-Soha, 2003). During the early COVID pandemic in the United States, press conferences typically blended presentations from governors, medical experts, and others engaged in COVID response effort, followed by a period of questions from the press. But the function of the conferences extended beyond conveying information. Press conferences became an important medium to display leadership, reassure the public, and foster collective efforts to slow down the virus, shaping the public response to the pandemic (Allcott et al. 2020; see also Holmes 2008; Taylor et al. 2009; Xu and Bernau 2021). With many Americans confined indoors as a result of pandemic fears and restrictions, COVID press conferences were televised and watched widely. New York Governor Cuomo received a 2020 Emmy Award for his daily press conferences. Although the award was later rescinded as a result of the sexual assault allegations, the press release from the academy awarding the Emmy noted that "People around the world tuned in to find out what was going on, and New York tough became a symbol of the determination to fight back" (Dwyer 2020).

Despite the ubiquitous use of press conferences, pandemic response was not consistent across states and local leaders took different approaches to communicating about the pandemic, including how they established COVID-19's main risks and impacts, how the pandemic would be managed, and the position of individuals as affected by the pandemic but also participating in mitigation efforts. Disagreements and inconsistencies arose as a result of the lack of national coordination (Gollust et al. 2020), often mirroring political leaders' party affiliation (Villegas 2020; Green et al. 2020). Partisanship, conflicting messages, and open disagreement in the face of public crises can undermine public trust in health institutions and government leadership (Shepherd, MacKendrick and Mora 2020), and undercut public 
support of and compliance with risk mitigation policies (Gollust et al. 2020). Recent findings have shown that political beliefs (Painter and Qiu 2020; Shepherd et al. 2020), political orientation (Stroebe et al. 2020), partisan differences (Allcott et al. 2020), and a strong faith in Donald Trump (Graham et al. 2020) influence peoples' compliance with health guidelines and mandates.

In this research, we use the concept of collective intentionality to shed light on how leaders call their constituents together and mobilize their prosocial behavior during pandemic press conferences. In doing so, we get novel insight into the connection between social groups, the social boundaries of the collective, and public compliance with health guidelines. We aim to uncover how collective intentionality is constructed in COVID press conferences and how it may differ across republican and democratic administrations.

\subsection{Collective Intentionality}

Collective Intentionality is a fundamental capacity of the human mind that develops early in life (Kern and Moll 2017; Tomasello and Rakoczy 2003), and entails the ability to engage in collective reasoning using a "we-perspective" (Tuomela 2013) such as "we are taking a walk" vs. "I am taking a walk" (Rakoczy 2017: 408). The concept of collective intentionality was developed by Searle (1990) and routinely studied in Phenomenology and Existential Philosophy (Schweikard and Schmid 2013). The concept was later brought into the Cognitive and Social Sciences through studies of cognitive development (see for overview, Rakoczy 2017) and some experimental work (Kirgil et al. 2021; McClung et al. 2017; Titlestad 2019). Recent experiments suggest that collective intentionality arising through spontaneous language usage in social interaction increases cooperation (Titlestad 2019; McClung et al. 2017). Language can foster cooperation by simplifying coordination problems, defining norms, rules and punishment, or reducing costs of monitoring compliance (Smith 2010: 241). 
Collective intentionality enables us to think and act as one within our social groups, making this a valuable theoretical concept for sociological research. Previous work (Bratman 1999; Searle 1990; Tomasello 2014; Kern and Moll 2017) indicates that collective intentionality can be examined at varying levels of analysis (e.g., individual reasoning or group characteristic), shedding light on cooperative behavior in small groups, organizations, and institutions. In this article we demonstrate an application of collective intentionality for sociology, with a focus on its contours in the real world of the COVID-19 pandemic. We develop a new measurement of collective intentionality by capturing the collective elements of language via computational text analysis and qualitative in-depth reading. Thus the objectives of this article are twofold: We firstly demonstrate the value of collective intentionality for sociological investigations, and secondly develop an approach to measuring the contours of collective intentionality on the macro level.

\subsection{Collective Intentionality, Leadership and Compliance}

Collective intentionality as an element of leadership in the COVID press conferences is a unique empirical case providing insight into how leaders motivate peoples' cooperation in an unprecedented moment - the onset of a global pandemic requiring a coordinated response and the participation of ordinary people. Previous research connects leadership styles, social identification and cooperation (e.g., Cregan, Bartram, and Stanton 2009). Moreover, research on charismatic leadership suggests that charismatic leaders commonly use references to collective elements in their speeches, such as shared history and collective identity, to emphasize their goal (Shamir et al., 1994), and they amplify these references during times of crises (Bligh, Kohles, \& Meindl, 2004). Similarly, research on leadership styles and sensemaking show that adoption of charismatic sensemaking styles were related to increases in COVID-19 infection rates (Medeiros et al. 2022). Though the existing literature shows that 
charismatic leaders commonly use references to collective elements in political speech and that sensemaking differs across leadership styles, less is known how political leaders draw on collective intentionality to mobilize prosocial action and if collective references vary based on political and cultural values. Thus, we study how political leaders across US states construct collective intentionality in COVID press conferences (RQ1).

Moreover, political affiliation (Shepherd et al. 2020; Stroebe et al. 2020; Allcott et al. 2020; Graham et al. 2020) affects peoples' compliance with COVID-19 health guidelines and mandates. A recent study suggests that both social conservatives and economic progressives show strong responses to COVID-19, but with different reasoning (Fischer, Chaudhuri, and Atkinson 2020): social conservatives being more worried and norm-enforcing, and economic progressives showing more cooperative and empathic responses. Likewise, framing is a key element of political speech and crisis communication that affects peoples' attention (Lagerwerf et al. 2015), attitudes toward cooperating with guidelines (de Blasio and Selva 2020; Gollust et al. 2020) as well as cooperative behavior (Crayne and Medeiros 2020;

Gollust et al. 2020). While no previous research examines collective intentionality in COVID-19 political discourse, some research finds little reliable evidence of value-related language differences between democratic and republican politicians (Neiman et al. 2016), while other work suggests a partisan divide in the COVID-19 tweets of members of US Congress (Green et al. 2020). We expect that the construction of collective intentionality is in line with the values of the party. Thus, we examine to what extent collective intentionality varies across states with republican and democratic governors (RQ2). 


\section{Data and Methods}

\subsection{Data}

The data for this research consists of a corpus of transcripts from governors' COVID-19 press conferences conducted in nine US states between March and April 2020, a period when politicization of the virus was not fully formed (Villegas, 2020). The text corpus contains press conferences ( $n=1124368$ words) from four Republican (Florida - FL, Maryland MD, Texas - TX, Ohio - OH) and five Democrat states (California - CA, Maine - ME, Nevada - NV, New Jersey - NJ, New York - NY; see Table A1). We collected text data via online transcripts: Firstly, we used the search strings "US governor COVID-19 transcript" in the google search engine and official US governors' websites for transcribed press releases in full text format (first hits include NJ, NY, MD and ME). Secondly, we searched for recorded live press conferences on Youtube by using "NameOfGovernor AND COVID-19".

Additionally, we use the JHU CSSE COVID-19 Data (Dong, Du and Gardner 2020) to assess infection and death rates during March and April 2020.

Lastly, we built a comparative pre-pandemic corpus by identifying prominent local US newspapers (Editor and Publisher International Yearbook 2000) across six US states and, for each newspaper, randomly sampling articles from five consecutive weekdays between July and November 2000 via the Newsbank (2020) archive. ${ }^{1}$ The pre-pandemic data consists of six US daily newspapers in each of six states (Alabama - AL, California - CA, Colorado CO, Georgia -GA, Louisiana - LA, Delaware - DE) of three republican (AL, CO, GA) and three democratic administrations (CA, LA, DE). Similar to the COVID-19 press conferences corpus, the pre-pandemic corpus was sampled right before the upcoming presidential elections in the year 2000.

\footnotetext{
${ }^{1}$ This data collection was part of another unrelated research project.
} 


\subsection{Measures}

There is no systematic and established approach to measuring collective intentionality in text. Collective intentionality has been operationalized differently via survey items (Kirgil et al. 2021), problem-solving tasks and games (Warneken, Chen, and Tomasello 2006) and transcriptions of conversations (McClung et al. 2017; Titlestad 2019), but previous approaches tend to be quantitative or context-specific. We determined that a more deductive approach that examines collective intentionality qualitatively would make it possible to build a robust measure that can be applied in different contexts. As discussed below, our analysis strategy makes it possible to assess the validity of the findings while also shedding light on the qualitative complexity of collective intentionality as expressed in our data.

We operationalize collective intentionality as the combination of we-talk evoking social ties and we-intentions linking social ties to prosocial behavior. We measure collective intentionality by analyzing the plurality in language via computational text analysis and its transmitted meaning via qualitative in-depth reading. More specifically, we use plurality in language to conduct computational analyses of collective intentionality in press conferences. Plurality in language can be identified through plural variables (e.g. they), plural constants (e.g. the Channel Islands), plural quantifiers (e.g. there are some things), plural membership (e.g. is one of, among) or collective plural predicates (e.g. met, wrote together; see Florio and Linnebo 2017: 455). When capturing plurality in language with machine learning, issues of lexical semantics arise. For instance, "we met in a cafe" consists of a collective plural predicate, however using machine learning to identify this predicate is problematic because a model can not differentiate different contexts such as "we met in a cafe" from "she met with misfortune". While the first example describes a collective plural predicate, the latter does not. Due to such issues of lexical semantics, and with no pre-existing measure of collective intentionality in language, we create a composite measure of plural words that are relevant in 
the context of the empirical data. Specifically, we compute a composite measure of plural pronouns (we, our), plural constants (state-names) and plural nouns (people). Plural pronouns and constants are derived from theory, and the grammatical tagging of text (Part of speech tagging) identified the most common plural nouns in the data. Then, a word embedding model (Skip Gram Model) analyzed the closest words around the identified terms (e.g., we, Marylanders, people) per state, creating standardized values of closeness. Word embedding models are recognized as being particularly well-suited for text analysis focused on meaning (Nelson 2021; Stoltz and Taylor 2021). Thus, the composite measure describes a set of words that revolve around context specific plural words that represent the construction of collective intentionality in the press conferences.

Additionally, we measure collective intentionality qualitatively via in-depth reading and coding. We developed a codebook of 15 codes, ranging from codes on action to we-talk (see overview Table A2). We coded in two stages. In the first stage, we developed an initial set of analytical codes based on theory and computational exploration that would allow us to explore the various ways that collective intentionality was created through the use of we-talk and other aspects of political discourse. We then coded a subset of the corpus individually. In the second stage, we compared our coding, discussed discrepancies, and refined the codes. At this stage we also introduced a few additional codes that emerged through the initial coding (e.g. discussions of inequality). We then divided the states and coded them. ${ }^{2}$

We assign political affiliation of the administration based on the governors' political parties. Some states may have a governor from a party that does not best represent the voters (for example, in recent years Maryland has voted democratically at the national level, but the governor is republican). A governor acts as a political representation of their party as well as the people they govern (Alexander, 2010; Bhatia, 2006; Schäffner, 1997). Political affiliation

\footnotetext{
2 Due to a disproportionately large corpus size of $\mathrm{NJ}$ and $\mathrm{OH}$, we coded around $30 \%$ of the $\mathrm{OH}$ text and used automated codes that were based on all other codes across states for NJ (incl. small parts of $\mathrm{NJ}$ itself).
} 
in the pre-pandemic corpus is assigned based on the outcome of the 1996 presidential election.

\subsection{Analytical Strategy}

This study uses different methods (i.e., computational text analysis, qualitative in-depth reading, pre-pandemic corpus and contextual data), which allows us to gather unique information, to calibrate the measure of collective intentionality and to prioritize the authenticity of the context (Turner, Cardinal, and Burton 2017).

Furthermore, we follow the inductive computational grounded theory approach, which is an interpretive method combining human and machine analysis of texts to produce more rigorous, transparent, and reproducible results (Nelson 2020). Computational grounded theory makes it possible to answer theoretical and qualitative sociological questions by developing large scale and reproducible analyses of texts. An ongoing process of verification and confirmation is central to computational text analysis (Nelson 2020). Computational grounded theory includes the steps of computational pattern detection, qualitative interpretation and refinement, and additional computational confirmation of the qualitative interpretations. For pattern detection, we use supervised (LIWC dictionary; Pennebaker et al. 2015) and unsupervised machine learning (Skip Gram Model in R; RStudio Team 2020) to detect the underlying pattern in our data. For refinement, using a codebook based on the computational results we coded the text in the qualitative data analysis program NVIVO (QSR International 1999). For confirmation, we compare qualitative and computational findings. We interpreted these results in light of the theory and previous research, triangulation through different methods, and using outside facts for verification. This interpretive work is presented along with the presentation of results. 
Some important methodological points must be emphasized concerning the analysis. First, we analyze the COVID-19 press conferences to uncover aspects of collective intentionality within the language used in those settings. As such we do not consider other aspects of the press conferences, such as their dramaturgical form (but see Villegas 2020), how the public responded, or the motives of political leaders and whether or not they spoke honestly and accurately. Furthermore, our method is not designed to rule out all possible interpretations of what is happening during the press conferences. Rather, it is designed to establish that our interpretation of the characteristics of collective intentionality within the press conferences is verified to the extent possible given the normal limitations of methods and data. Lastly, we recognize that we-talk and we-intentions associated with collective intentionality can (re)produce social inequality by erasing or actively excluding people and groups from the collective "we." Our analysis incorporates attention to the boundaries of the collective as it relates to inequality, but is not an exhaustive study of inequality as observed in the press conferences.

\section{Results}

The research was conducted in line with the stages of analysis in computational grounded theory: computational pattern detection; qualitative interpretation and refinement; and computational confirmation. In presenting the results, however, we deviate from this format in the interest of our focus on the use of collective intentionality within the press conferences. 


\subsection{Pattern Detection: Characteristics of COVID-19 Press Conferences}

\section{Corpus}

We conducted a variety of exploratory computational analyses in order to uncover patterns in the corpus. In order to ground the analysis, we also considered specific aspects of each state's situation at the time of the press conferences.

In March 2020, the highest infection and death rates appeared in NY, NJ and CA, with infection rates in NY being between 5 to 20 times higher than in other states (see Figure 1). After the declaration of a national emergency on March 13, CA issued the first statewide and mandatory Stay-at-Home Order on March 19, soon followed by NJ and OH (see overview Moreland et al. 2020). In our sample, democratic administrations tended to introduce mandatory Stay-at-home orders earlier and more strongly than republican administrations.
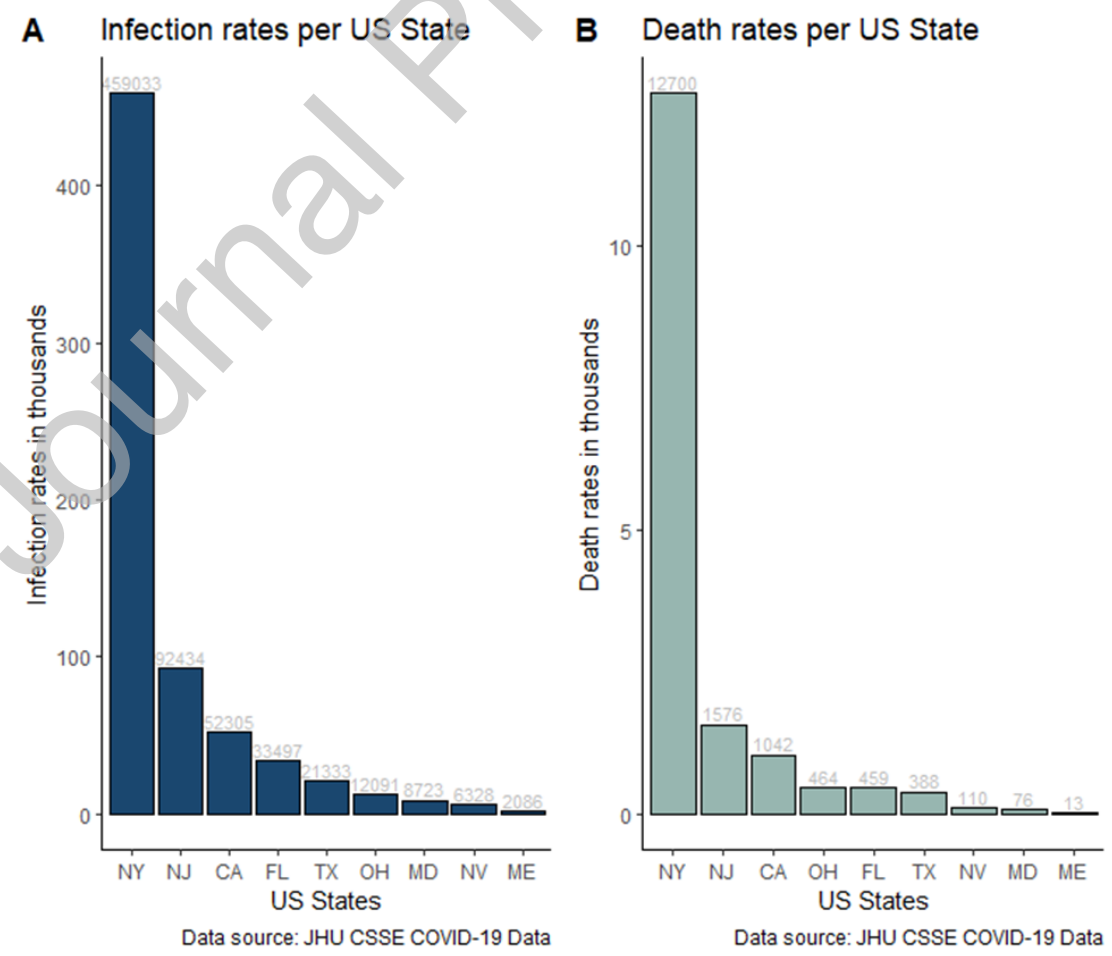

Figure 1. Two plots A and B show the total infection and death rates across states (per thousand) until March 31, 2020 using JHU CSSE COVID-19 Data (Dong et al. 2020). 
The press conferences varied in form, length, and frequency across states. The COVID-19 corpus varies in size per state with NJ presenting the largest and ME the smallest corpus (see Figure 2 Plot A), which is related to the sampling strategy and availability of data. Similarly, the states differ regarding the setup of the press conferences, including using various mediums (radio, video and/or text online) and speakers (e.g. governor's, guest speakers, Q\&A sessions with reporters). The most common format across states is the governor's addresses with invited guest speakers and Q\&A sessions (see Table A1 for overview).

A Corpus Size by US States

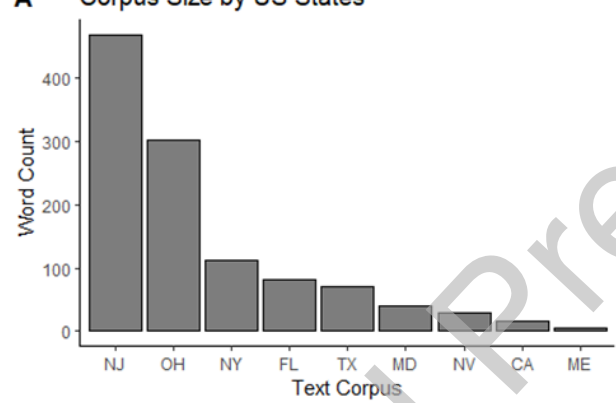

C Authentic Language Use by US States

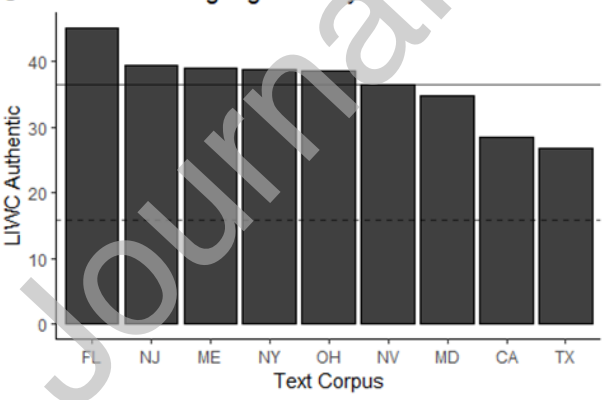

B Analytical Language Use by US States

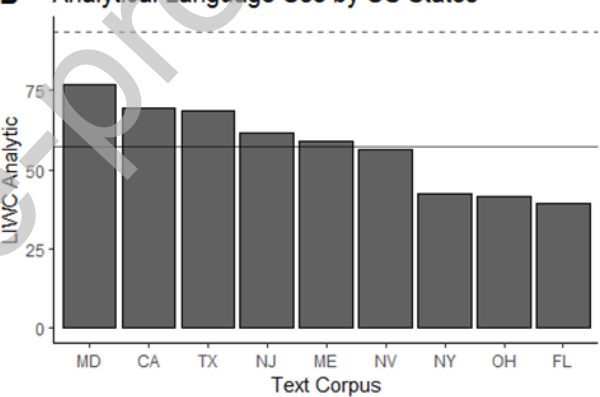

D Tone by US States

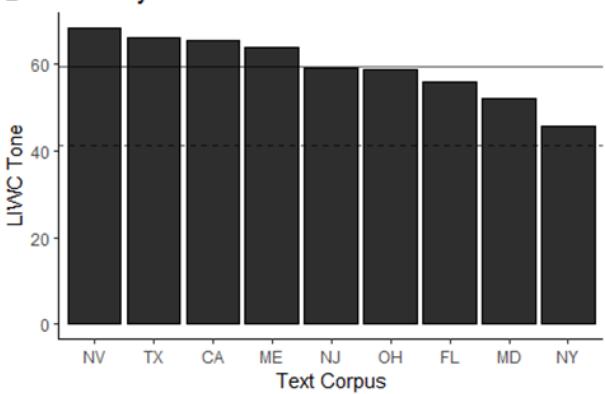

Figure 2. Characteristics of COVID-19 corpus across nine states. Plot A. Corpus size by US states (in thousands). Plot B. Analytical language usage with an average of $57 \%(S D=13.64)$. Plot $C$. Authentic language usage with an average of $36 \%$ (SD=5.68). Plot $D$. Tone of voice with an average of $60 \%$ ( $S D=7.41)$, indicating a positive tone on average. Note: The solid line presents the mean of the covid-19 corpus, while the dashed line presents the mean of the comparative corpus.

Lastly, pattern detection using LIWC Dictionary uncovered differences in the language use of the press conferences across states, and the differences between language use in press conferences compared to the pre-pandemic corpus. LIWC is a natural language 
processing dictionary that is recognized for its high-quality assessments of the psychological properties of language, including elements such as expressions of sentiment, leadership and honesty (Pennebaker et al. 2015). LIWC provides the percentages of the text corpus matching the psychological properties of terms in the dictionary. Pattern detection with LIWC uncovered no systematic differences across political parties, but evidence that the press conferences are different from other corpora.

The results show that press conferences in MD, CA and TX possess a highly analytical discourse, while in other states such as FL, OH and NY press conferences contain more informal narratives and personal experiences (Plot B). The press conferences also show different levels of authentic talk, characterizing a more personal, humble and vulnerable language (Pennebaker et al. 2015). For instance, FL and NJ reveal substantially more honest language usage in comparison to TX and CA (Plot C). The press conferences possess a positive tone, except for NY with a value below 50 indicating a negative tone of voice (Plot D). Differences in language use appear independent of political parties, both in the press conferences and in the pre-pandemic corpus .$^{3}$ LIWC analyses did show that, i n comparison to the pre-pandemic corpus , the COVID19 corpus is on average less analytical , more authentic , positive (vs. negative), and displays less leadership (see Figure 2).

\subsection{Qualitative Interpretation and Computational Confirmation: Collective}

\section{Intentionality in COVID-19 Press Conferences}

Having uncovered some basic patterns in the texts, we turned toward examining collective intentionality in the press conferences. Comparing the word embeddings of collective

\footnotetext{
${ }^{3}$ The LIWC word scores (in percent) reveal no noticeable differences between democratic and republican administrations both in the COVID press conferences (e.g., difference in analytical speech of $1.3 \%$, authentic speech $0.94 \%$ or tone of voice $2.3 \%$ ), and the prepandemic corpus (analytical of 0.05 , authentic speech of 4.29 , and tone of voice 6.18 ).
} 
intentionality across US states, we find cross-state similarities regarding the characterization of the collective. Figure 3 shows the terms most related to collective intentionality in each state. There is a high level of overlap of terms relating to the collective (e.g. the usage of "we”, "people”, and “our”). State-based names (e.g. Marylanders or Jerseyian) also played an important role in describing the collective and being among the closest words to collective intentionality. We also identify different characteristics across states: while some states present an active and progressive front (e.g., confident, aggressively, pushed such as in CA, NY, NJ) others display more informative characteristics (e.g., continue, hope, visit such as in TX, OH, MD; see Figure 3).

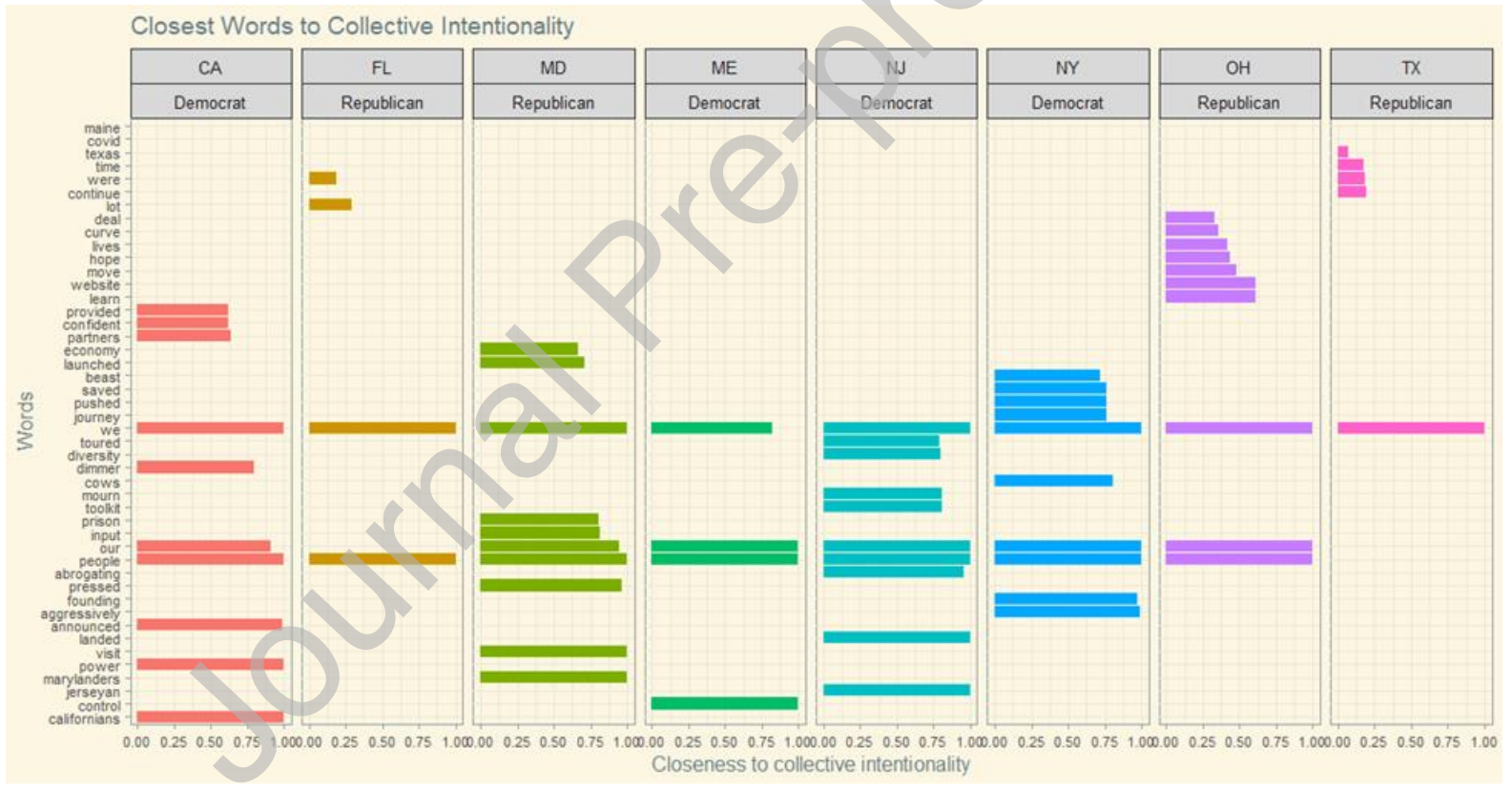

Figure 3. Closest words to collective intentionality across states based on the Skip Gram Model.

Our qualitative analysis and interpretation of the texts made it possible to refine our understanding of collective intentionality in the press conferences. Guided by codes based on computational pattern detection, the qualitative analysis focused on the nature of we-talk and its relationship to different types of action, social boundaries, threats, and limitations. We 
observed collective intentionality qualitatively through the combination of the specification of the collective and a related reference to action, obligation, responsibility, or self-sacrifice. For example, Maine's democratic governor Janet Mills provides a good example of we-talk and its link to collective intentionality:

It's in difficult moments like these, when these burdens feel sometimes too great to bear, I think of the quote from my four-year-old granddaughter Noelle's favorite movie, Frozen 2. Maybe you've seen it. The quote is: "Do the next right thing." What keeps me going during these times, during this Holy Week for Christians, Passover for people of the Jewish faith, it's my faith in you, in Maine people: my faith in knowing that, no matter the difficulty, no matter the challenge, Maine people will rise to do the next right thing. So, today, I suggest you call a neighbor, make sure they are okay. Thank our front line workers, our health care workers. Hug your kids, they are missing their friends and their teachers and schoolmates. Stay the course. Stay home to beat this virus. Be kind and love one another. I am speaking to you not just as your Governor, but as a widow, as a mother, as a grandmother, as a friend. (ME)

We observe we-talk linked to collective intentionality across all the states and the party divide. For example, republican governor Gregg Abbott of Texas remarked:

In typical Texas fashion, you have come together to support one another. You've made personal sacrifices to ensure that our state slows the spread of covid-19. You helped to reduce the number of Texans who needed hospital care. You truly helped to save lives. Now Texas needs you to continue those efforts. 
In these quotations, Governor Mills evokes commonality, co-identification, sympathy, compassion, and, quite importantly for the intentionality aspect of collective intentionality, the belief that those connections and emotions imply a call to action. Mainers' self-sacrifice in the service of doing the "next right thing" for one another. Likewise, Governor Abbott combines membership as Texans with the self-sacrifice required by public health requirements. However, not all instances of we-talk evoked collective intentionality. Take, for example, this discussion of the health care situation in California, which also uses wetalk, but is not associated with an intention toward collective action:

We, in California, are uniquely positioned because of the National Institute of Health, four of the top 10 funded NIH sites are in the State of California. We are blessed and endowed with some of the finest research institutions and hospitals (...) (CA)

The evidence suggests that governors were aware of the link between collective identification and prosocial action. For example, California's democratic governor Gavin Newsom made the link explicit: "We can create the kind of dynamic sense of commonality that ultimately will get us through this moment" (April 21, 2020). Computational confirmation corroborated Governor Newsom's insight. The other qualitative codes that coincided most with we-talk were Social (r=.87), Action ( $r=.72)$, Future Action ( $r=.70)$ and Inequality $(r=.65)$.

Although we observe a common baseline of collective intentionality through we-talk across the states, there are also differences both within and across states, as reflected in the qualitative and computational results. We interpret different aspects of collective intentionality as pertaining to the characteristics of unity and collectivity, challenges and risks facing the collective, differences in how power and agency are discursively distributed, and the social boundaries. 


\subsubsection{Unity and Collectivism}

Governors characterized the collectivity through appeals to unity and group identity at the level of family, neighborhood, community, and state. These appeals to collective identity tended to point out that we are all in this together, often using analogies to emphasize interdependence such as being "in the same boat" (CA) and citing a baseline human connection:

There is a codependency and a mutuality among people in society that is more clear and distinct than we have ever seen it. You sneeze, I get sick (...) It is that close a connection. (NY)

However, given the venue, public addresses from the leader of the state, it should be no surprise that state-based identities loomed large in many of the press conferences: For instance, in Maine as "We will get through this because we are Maine", in Maryland as "We are a proud state. We are a hard-working state" or in Texas as "This is a reminder about who we are as a people. We're Texans".

\subsubsection{Vulnerability, Impacts, and Recovery}

Vulnerability and risk were related to collective intentionality. Naturally, the pandemic was frequently described as a health crisis, in particular in terms of the capacity of the health system to meet the current and anticipated needs for care. The pandemic was also described as an individual health risk. It was quite common to talk about vulnerable groups:

We must make sure we protect the most vulnerable Californians, our seniors in skilled nursing facilities, nursing homes, assisted living centers, those that are vulnerable out 
on the streets and sidewalk, the homeless, people with compromised immune systems. (CA)

In general, a discussion of vulnerability to the virus focused on health preconditions, while the risks resulting from social inequality (e.g. resulting from mass incarceration, working conditions, etc.) were less frequently discussed (see discussion of inequality below).

Beyond the health impacts, there was significant discussion of other social and economic effects. Not all states were experiencing high levels of COVID-19 transmission and hospitalization at the time of the press conferences, and states also experienced the economic impacts of the pandemic differently. In places such as Florida and Nevada, there was concern about the rising number of COVID-19 cases, but the most widespread impact in those early months was the shuttering of the tourism industry, throwing many people out of work and negatively impacting individuals', businesses, and states' economy. Likewise, the Texas governor tended to emphasize the economic impact of the pandemic on the oil industry, which he called the lifeblood of the state. When governors emphasized such impacts, they tended to talk about suffering small businesses, business owners, and workers:

I'm mindful, about very much of all of the individual workers who have been displaced by this, by this sudden shock to the system. These are folks who were working hard, doing right things, and through no fault of their own found themselves in a state of unemployment. I think even more than the economic is the kind of emotional toll because you don't know what's going to happen and are not sure where money will come from. (FL) 
Economic-focused discussion of coronavirus response also tended to emphasize the efforts being made to facilitate rapid payout of unemployment insurance money, and to begin economic reopening and recovery: "We want to be a part of the solution and helping the oil and gas sector here in the state of Texas" (TX).

Alternatively, when governors maintained a focus on the pandemic as a health crisis, the discussion of the impacts tended to focus less on economic stressors and more on emotional and social hardship of lives thrown into chaos:

People are frightened, they're anxious, they're stressed, I mean think about it. It's unprecedented, you're at home, you're trapped, you're afraid to touch another human being, you're not getting a paycheck. (NY)

And in such cases, discussion of recovery from the pandemic generally downplayed economic recovery, or at least discussed economic reopening in tandem with the elimination of health risks:

Public health creates economic health. I repeat: public health creates economic health. That is what will guide us. That's the order in which we must proceed. It means that before we reopen non-essential stores and businesses, before we can reopen our parks, or before we allow in-person dining in our restaurants, among any host of other activities, people need to know first and foremost that their health, that your health, will be safeguarded from COVID-19. (NJ)

\subsubsection{Action and Efficacy}


Governors made frequent calls for action and applauded the prosocial behavior of people, businesses, communities, healthcare and other frontline workers, members of the military, and political leaders who assisting with or crucial to the pandemic response:

Everybody has a role to play. Everyone has to do their job. And we have to cooperate and work together. And if I believe you're doing your job, I will say it. And I will thank you. If I believe you're not doing your job and you're not being helpful where you should, I will say that too. (NY)

Prosocial action and sacrifice were key elements of the prosocial behavior mobilized in the press conferences, but there were differences in the types of action, types of actors, and aspects of power and efficacy emphasized. Volunteerism was a major theme. Multiple states called for a "mobilization" of a "volunteer army" (CA) and set-up websites that coordinated volunteer efforts, including activities that did not require special skills like assisting in the collection and distribution of emergency food, but more often focusing on recruiting and mobilizing people with specialized training or resources. Governors sought volunteers who were trained medical professionals able to assist with the provision of health care and development of testing capacity, factory owners who could leverage their manufacturing capacity to produce scarce and necessary equipment, and members of the business community who could assist in building the necessary supply chains for that manufacturing.

For the average person, the action most governors sought was "do you part: stay apart" (ME) and "to work together while remaining apart" (TX). The sacrifice demanded was to act responsibly: "to stay at home, keep social distancing and flatten the hell out of that curve to get it as close down to that red line as humanly possible" (NJ). There is a tension 
between the emphasis on efficacy and collective action, on the one hand, and the fact that, for ordinary people the best action was usually a particularly demanding type of inaction:

You've been staying home for Nevada. You're wearing face coverings and protecting your families. You are the reason we have avoided thousands of deaths and a breakdown of our health care system. You heeded calls to follow the directives and saved lives. Yes, you saved lives. (NV)

Given that leadership moments like these press conferences usually incorporate a call to action, from the perspective of the intended audience, there could be conflict read into mobilization of collective intentionality in this instance. The notion of prosocial action is fundamental to the way that collectivities are characterized in the press conferences, and governors connect the moment of the crisis of the pandemic to other moments demanding mobilization and sacrifice such as calls to war or requests for volunteers to assist with disaster recovery. However, what the governors actually want from people during the pandemic is to engage in actions that violate the common form that such mobilizations take and could be interpreted as undermining the everyday connections upon which shared commitments and collective identities are usually built and expressed: "We stayed home, we missed school, we missed our friends, all of our normal routines, so we could fight this virus and save lives." (MD) The potential conflict arising from collective intentionality and the particular prosocial action required by the pandemic could lead some people to instead prefer more explicitly action-oriented covid responses tied to economic motives such as returning to work, supporting local and small businesses, and reopening shuttered restaurants and tourist destinations. 


\subsubsection{Boundaries}

Governors acknowledged that there were multiple, nested and sometimes overlapping or even conflicting collective commitments that could undercut cooperation in responding to the pandemic. For example, Governor Cuomo drew upon many of these levels and noted the importance of overcoming localism or regionalism within his state:

You get to really see how a person responds at a time of crisis. You get a little snapshot of their character and of their foundation. It's also true of the collective, also true of society. And when I say we have to move to help Western New York, yeah, there will be some places in the state where you hear a voice that says, "No, no, no, we have to worry about ourselves. We have to take care of us and they're on their own the way we're on our own." Not in New York. That's not how we operate. Nobody is on their own. We are one state, we are one family, we are one community, and we're there to help one another. (NY)

In addressing collective commitments within the state or the nation, the COVID press conferences provided an opportunity to specify the boundaries of the collectivity, often through a discussion of those who were not included in the "we" of the governor's we-talk.

These boundaries of community and collective commitment were visible in the recognition that those who were vulnerable during the pandemic deserved love and support. In some cases, governors drew a moral boundary between friends and neighbors in need who were implicitly contrasted with those who normally require social support and were not extended the same benefit of the doubt: "I think it's a shame if we have our friends and neighbors go out of business through no fault of their own" (FL). Governors used this line of 
reasoning to justify policy changes such as removing the normal limitations on access to unemployment insurance, free healthcare, and freedom from eviction.

In some cases governors created a boundary between the collective and the people of other states:

States that comply and those who do not: with all due respect to the states that aren't remotely as compliant as we are or as New York is by example, we're not going to go through this pain together, folks, and break the back of this curve - flatten it, break it, bring it down, and begin to open up again just to be exposed to the lowest common denominator. (NJ)

With such framing, governors justified collaborations with some states and not others, and rationalized closing the border to some states in the interests of protecting "our own."

Anybody traveling from those regions in New York, New Jersey, to the state of Florida, will have to do a mandatory 14-day self isolation. That is the only way we could be sure that that virus is not going to be too many people sacrificed, to try to protect our friends and neighbors. (FL)

The boundaries of the collective were also evident in the way governors engaged the topic of social inequality. Inequality was mentioned, but rarely emphasized. This is surprising because the virus disproportionately caused more deaths in minority groups. When these inequalities were discussed, there were differences in the extent to which vulnerable socially and economically excluded groups were seen as part of the we of a governor's we-talk. For example, New York's Governor Cuomo points out "the disparate effect of this disease and 
how it reinforced the disparity in the inequity in society." He argued that COVID inequality is an artifact of the segmented labor market:

Two-thirds of those front line workers are women. One-third come from low-income households. So they've been doing this work, they've been stressed, they're going home to a household often that had two wage earners, one of them is now not working, they're living just on that one salary. And, after all of that, we see the infection rate among African-Americans and brown Americans higher proportionately than other groups. Why? Because they were out there exposing themselves. That's why. You can talk about health disparities, et cetera. But, I believe all the studies are going to wind up saying, "Yes, when you were home with your doors locked, dealing with cabin fever, they were out there dealing with the coronavirus" (NY).

Cuomo's engagement with this topic was atypical in its understanding that COVID inequalities were not merely an aberration. What was more common was the idea that the inequalities revealed by the pandemic were short term problems:

One of the things we noticed with the drive through sites is not everyone necessarily has access to or owns a car. I know Florida is very car centric, but not everyone does. So we first went into a public housing project (...) and we supplied the swabs and testing kits (...) and it was a walk up concept (FL)

Few governors took up the topic of the risks the pandemic posed to socially vulnerable groups such as the prison population, the homeless, and undocumented immigrants. California did announce outreach efforts to reach the State's relatively large homeless and 
undocumented residents. In terms of the prison population, Maryland's republican governor took an aggressive stance on protecting the prisons by releasing low-risk inmates:

You know, we lowered our prison population more than any state in America (...) Since the crisis started, I believe we've reduced another 2300, we've taken almost all the actions that people are recommending. Secretary Green has been amazingly aggressive in our effort to try to protect our prison staff and our prison population (MD).

But most states avoided the topic or in other ways implicitly or explicitly placed the incarcerated outside of the boundaries of the collective. $\mathrm{OH}$ had widespread outbreaks in prisons and mobilized resources to protect prison workers so they did not carry the virus home from work, but did not express concern for spread among the prisoners. Florida governor DeSantis dismissed concerns for the prison population:

Some of these other states have been really releasing a lot of people. Some of these people are very dangerous. I don't see how, in a time of pandemic where people are on edge already, releasing felons into society would make a whole lot of sense (FL).

\subsection{Qualitative Interpretation and Computational Confirmation: Comparing}

\section{Republican and Democratic Administrations}

We conducted multiple analyses geared toward examining whether and how the press conferences and collective intentionality in the conferences varied across party lines. In terms of general pattern detection , the LIWC results from the pattern detection showed no differences in the psychological properties of language usage across republican and 
democratic administrations (see Figure 2), however the results from the word embedding models did show differences between republican and democratic administrations with regard to collective intentionality. Figure 4 consists of an overrepresentation plot that provides a more accurate comparison by accounting for the varying corpus sizes of each state (see Figure 4 ). The figure shows that Republican administrations focus more on the collective (we, our, people, home), unemployment and businesses, compared to democratic administrations. Both republican and democratic administrations are on shared terms in relation to entities (e.g., government, communities, families) and words related to describing the virus and medical system (e.g., daily, dr., disease).

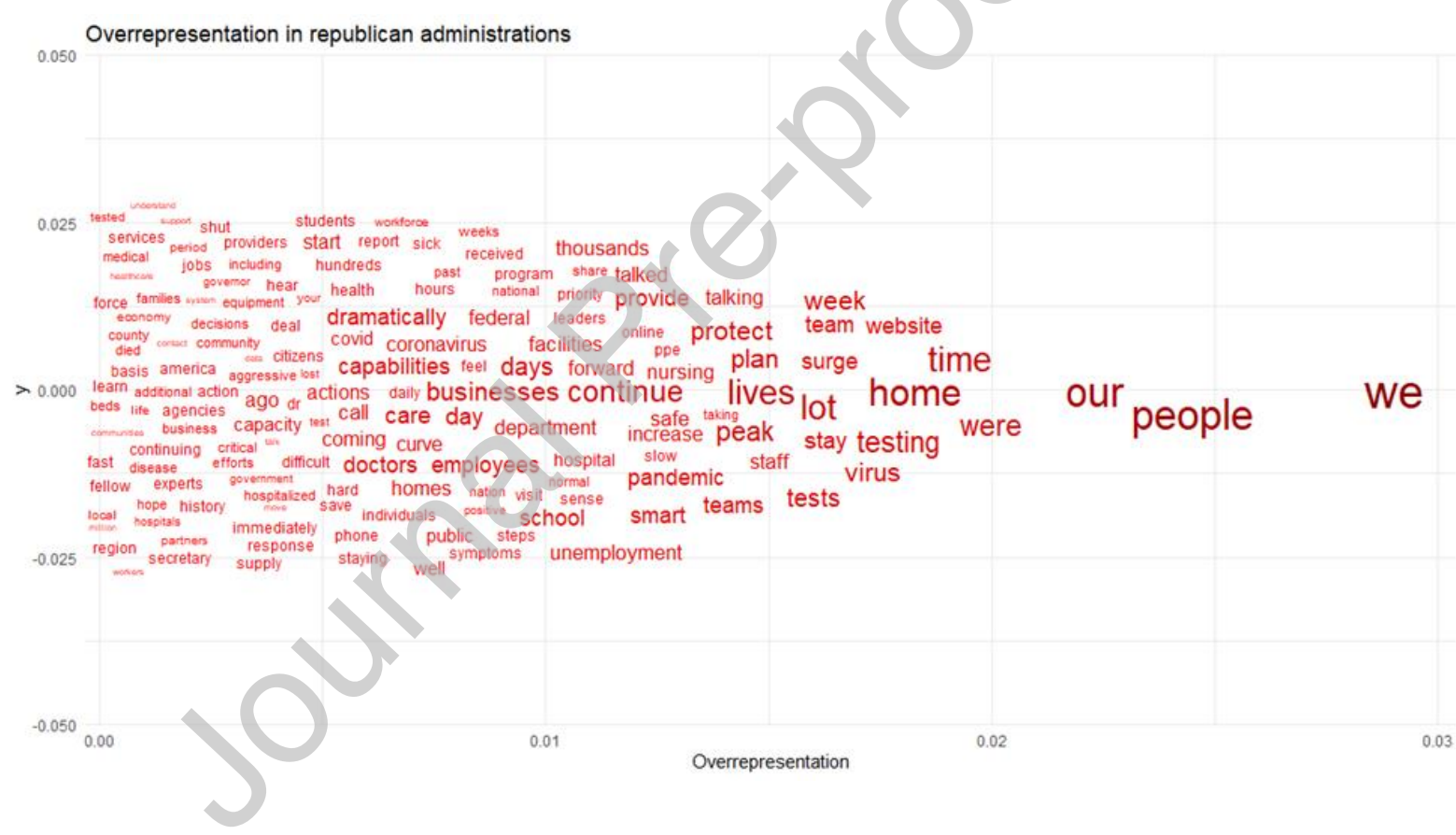

Figure 4. Overrepresentation of collective intentionality-related words of republican administrations compared to democratic administrations. Values of 0 on the $\mathrm{x}$-axis suggest equal usage of words, while larger values and word size show an overrepresentation of words in republican administrations compared to democratic administrations.

\subsubsection{The Collective}

The qualitative analysis confirmed and refined our interpretations of political differences in collective intentionality. The collective is depicted as self-sacrificing in both republican and 
democratic administrations. In democratic administrations, the sacrifice refers to agency and action on the individual level, such as people's prosociality, volunteerism and adhering to guidelines. By clearly addressing individuals' contribution, the governors shape the we by making such actions a defining characteristic of the collective (e.g., this is how Nevadans are). By emphasizing the role each individual has to play and sacrifice for, indicates a bottom-up approach to tackle the pandemic. For instance, the governor in California states

So this is a spirit of communitarianism, individuals contributing to their community. It's the spirit of recognition that we're all in this together. It's the spirit that has allowed California to bend the curve. (CA)

Similarly, the governor in Nevada frames the characteristics of the collective by explaining that

Nevadans took this seriously, and I'm proud of you. You've been staying home for Nevada. You're wearing face coverings and protecting your families. You are the reason we have avoided thousands of deaths and a breakdown of our healthcare system. You heeded calls to follow the directives and saved lives (...) The actions we are all taking going forward will determine if we continue with this success. (NV)

In democratic administrations individuals' actions are framed positively as a sacrifice to the collective, thus linking the characteristics of the collective to individuals' agency. Although such a positive frame of individuals' sacrifice through action also occurs in republican administrations to some extent, action on the individual level tends to be overshadowed by the detailed elaboration of state-level action and the passive role of individuals. For example, the more passive nature of an average Floridians response to the pandemic is highlighted when Florida governor noted the unprecedented need for new television programming: 
I think that we do need to support content, like especially sports and events. We're not going to have crowds there, I get that, but if we can do like if NASCAR does a race and can televise it without having a large crowd, I think that's a good thing (...) Put that on TV. I think people have been starved for content (...) If people are being told to stay closer to the house, it sure does help to have some fresh things to be able to do. (...). I mean if you think about it we've never had a period like this in modern American history where you've had such little new content, particularly in the sporting realm. I mean people are watching, you know, we're watching reruns from the early 2000s. (FL)

Republican administrations report more action in the press conferences by presenting more detailed elaborations on actions undertaken by the state and by private industry to tackle the pandemic, while individuals follow health guidelines. Although democratic administrations also present their actions on the governmental level, they tend to focus more on the agency of individuals, such as engaging in volunteering (e.g., "Everybody has a role to play. Everyone has to do their job", NY). Individuals are actively included in the action in democratic administrations, while action in republican administrations revolves around the actions on the state level to respond to the pandemic. In republican administrations, a top-down approach emerges with the state government taking action to tackle the pandemic in ways that are separate from people complying with the guidelines, in contrast to the democratic bottom-up approach.

In republican administrations, people's sacrifice is more frequently presented as incorporating the loss of work in addition to people's hard work to fight the pandemic: "You've got to put that aside and work for the common good and that's what we've done" (FL). Although the government is in charge of fixing the pandemic, individual contributions 
are often referred to as work (e.g., work for the common good). Compared to democratic administrations, work is very dominant in republican administrations as an identifiable characteristic of the collective such as in Florida and Texas

You throw hundreds of thousands of people out of work. We tonight know what effect it would have on the economy, public health, by people affected by it even if you did have a benefit. (FL)

Texans really want to get back to work. It's kind of part of the Texas DNA, and there's been a yearning to work ever since the first day that work was shut down. (TX)

Issues around work are more discussed in republican than in democratic administrations (e.g., safety in the work environment, reopening plans, businesses). Thus, democratic administrations define the collective by peoples' sacrifice related to their agency and actions, suggesting a bottom-up approach. In contrast, republican administrations characterize the collective by peoples' sacrifice of work and in adhering to guidelines, as well as governmental action on the state level, indicating a top-down approach.

\subsubsection{Social Aspects and Inequality}

In both republican and democratic administrations, keeping "loved ones safe" plays a fundamental role in reasoning for fighting the pandemic. Both administrations also acknowledge the disparities in the consequences of the pandemic of different minority groups, such as black and brown communities. However, although social solidarity is pronounced in the corpus, health inequalities are generally not elaborated in detail. Instead, governors report analytically: "The racial data is consistent and troubling, as it has been since we've been reporting it" (NJ) or "Early data shows that virus is disproportionately impacted that the virus has disproportionately impacted non-white Texans many of them low-income" 
(TX). Both republican and democratic administrations acknowledge the severity of such inequalities, however the inequalities 1) receive less attention compared to other vulnerabilities and 2) are reported without a high degree of intensity or emotion. In comparison, consider the emotional tone with which the Ohio governor discusses students missing out on social activities:

I can't express how sorry I am about that I know how much many of these activities all of these activities mean to to to young people I mean you know as an athlete this is his or her senior year and to miss the spring sports. $(\mathrm{OH})$

Although social ties function as the reason to tackle the pandemic, social disparities in minority communities (also being part of such social ties) do not receive the same attention as other issues.

\section{Discussion}

The present study uncovered how political leaders constructed collective intentionality in COVID press conferences (RQ1) and its differences across republican and democratic administrations (RQ2) in nine US States. The mixed methods study used various methodologies to enhance the theory development and to gather unique and relevant information. Following a computational grounded theory approach, we combined human and computational text analysis to answer research questions that are interpretive and qualitative in orientation while leveraging both qualitative insights and quantitative power (Nelson 2020). For our first research question, we found that political leaders evoke collective intentionality by emphasizing unity, vulnerability, action, and community boundaries. For our second research question, we found similarities across party lines regarding how boundaries and social inequalities were discussed, and differences in the role of individuals as part of the 
collective pandemic response. Specifically, our three key findings are that 1) leaders' call to collective action collides with the inaction required by health guidelines. 2) Across political party lines, social inequalities receive little attention compared to other themes. 3) Collective intentionality in democratic administrations was linked to individuals' agency and actions. Conversely, in republican administrations individuals' contributions were downplayed compared to work and state-level action.

This study does have limitations. Analysis of our qualitative coding showed limited intercoder reliability. We believe that this limitation should be considered in light of our methods. The state-by-state characteristics of the press conferences did not lend themselves to easy compatibility for the purposes of coding. Further, the qualitative coding was not used to generate statistical results such as the number of codes or percentage of text assigned to particular codes. Instead, coding was used to index the corpus for further qualitative interpretation and analysis, for example, queries about the codes within codes and comparing the text codes. Following the computational grounded theory approach, we used computational techniques to reliably test the validity of the findings of the qualitative analysis (Nelson, 2020). For example, we independently observed the dominant work theme in republican administrations both qualitatively and computationally. It should also be noted that democratic states were slightly overrepresented in our corpus. Furthermore, our findings pertain to the nine states that we studied, and are not generalizable to other states. Nongeneralizability of the findings does not present an obstacle since the aim of the present paper was to assess the empirical link between collective intentionality in press conferences across states and political affiliation. Subsequent work can examine the differences of collective intentionality across state and national boundaries to show how collective intentionality varies across contexts and is influenced by political affiliation. Our findings lay the ground for developing text-based indicators of collective intentionality. . . Lastly, due to 
variations in size and form of the press conferences, the number of words extracted in the Skip Gram Model ( $n=8)$ may not represent each text equally well. However, the comparability among text corpora received a higher priority than using a unique number of words for each corpus since our mixed-methods design allowed us to correct for this issue by gaining unique information through in-depth reading.

The research makes several theoretical, empirical and methodological contributions. We demonstrate the value of collective intentionality for sociological research. By connecting collective intentionality in leaders' pandemic press conferences and its public compliance with COVID-19 guidelines, our application goes beyond the cognitive elements traditionally associated with collective intentionality to show that collective intentionality plays an important role in social life and culture. For example, research on charismatic leadership has highlighted the importance of collective elements regarding the content of speech (Bligh, Kohles, \& Meindl, 2004; Shamir et al., 1994). Using the theoretical framework of collective intentionality in charismatic leadership research may help to uncover how charismatic leaders differ in their use of collective elements to mobilize action and define the boundaries of the "we" based on their political, moral and cultural values. Thus, collective intentionality is a crucial element of cooperation that provides theoretical and empirical insight into real life phenomena.

We developed a new method for capturing collective intentionality using computational text analysis and qualitative coding. For computational text analysis, we used part of speech tagging to identify the most common plural nouns in the corpus and then manually created a composite measure of plural words that are relevant to the collectivities in question in each state. For the purposes of qualitative coding, we determined that collective intentionality can be identified through the combined use of "we talk" referencing or 
specifying the collective, and a related reference to action, responsibility, or self-sacrifice. These methods could be used in other research into collective intentionality in other natural language and real-life contexts.

Examining collective intentionality in COVID press conferences provides a view of similarities in form and substance that speak to the bipartisan and solidaristic nature of crisis leadership (Villegas 2020). Collective intentionality is used across context and party affiliation. The press conferences conveyed more expertise, and were less analytical, more authentic, and more positive than a pre-pandemic comparison corpus. Although language use varied across the states, we find no relationship to the political leanings of the state, which is in line with some research (Neiman et al. 2016) but not with others (Hart, Jarvis, and Lim 2002). Such differences across studies may result from the nature of text data (e.g., COVID19 press conferences vs. presidential campaign speeches). All states tend to link collective commitments with calls to action, and at least some governors were aware that mobilizing prosocial action by emphasizing collective intentionality was a purpose of the press conferences. These findings are in line with previous research (Gonzalez, Metzler, and Newton 2011; Cregan, Bartram, and Stanton 2009). Unity at the level of the state was most commonly emphasized, but there was also some attention to more local and personal ties. Furthermore, collective intentionality was also associated with discussion of the problems and vulnerabilities caused and exacerbated by the pandemic, the prosocial actions that the governors desired and claims about the efficacy of citizen action, and specifications of the boundaries of the collective, excluding, for example, people and states interpreted as posing a risk to the well-being of the governor's own state.

Despite the underlying solidaristic and prosocial undertones of the press conferences, there was limited attention to social inequality. Although some states put in place measures to 
extend support to structurally vulnerable populations such as the homeless, undocumented immigrants, and the incarcerated, these acknowledgements of inequality were generally delivered in a less emotional tone. In the press conferences, it was rare for a governor or other speaker to acknowledge COVID inequality as an extension and reflection of ongoing inequality and injustice.

Collective intentionality provided a window into the relationship between compliance with COVID restrictions and political leanings. Although there was much in common across the political divide when it came to a shared emphasis on the virus, the health system, and the collective entities of family, community, and state, republican and democratic administrations did vary in their focus, with republican administrations placing more emphasis on business, unemployment, and schools, and using collective terms more frequently. In democratic administrations, there was more emphasis on prosocial action on the part of individuals, while in the republican administration, ordinary people were given a more passive role as people thwarted in their desire to work and in position of, perhaps bored, compliance with stay-at-home orders.

Collective intentionality might not only foster cooperation (Kirgil et al. 2021; McClung et al. 2017; Titlestad 2019), but also unintentionally create conflicting motivations. Differences in how individual action and agency is framed sheds light on republican and democratic differences in public compliance with and/or hostility to coronavirus restrictions. The clash between the call to collective action and the inaction required by health mandates results in conflicting messages and may depress people's compliance with recommendations. Our research shows a difference between democratic and republican administrations in how governors framed the agency and efficacy of individuals' prosocial behavior. Democratic governors were more likely to treat ordinary people's compliance with the recommendations 
as a call to action in the form of staying home to save lives, and elevated to equal importance as government, healthcare, and industry actions. Such a framing connects staying at home to fundamental ideas of ordinary people making extraordinary sacrifices. In republican administrations, however, this particular crisis resulted in more of a call to inaction among ordinary people, especially relative to the high-level work of political and economic leaders managing the medical system and planning for economic recovery emphasized in the press conferences. In republican administrations, it is not hard to imagine that the motivation to stay at home is undercut by individuals' desire to engage in a more active response consistent with the economic goals of re-opening the economy and getting back to work.

The concept of collective intentionality is valuable for research on cooperation and leadership in small groups, organizational settings and collective action on a larger level, and contributes to a greater understanding of social phenomena. Future research can continue the theory development, develop its measurement, assess other contexts, and empirically test the findings of this study across all US States.

\section{Author Contribution}

Z.M.K. and A.V. wrote the Introduction, Results and Discussion section, and performed the qualitative coding. Z.M.K. collected the data, wrote the Methods section and performed the computational and quantitative analysis with input from A.V.

Data Availability

Data and codes can be found at https://github.com/ZMKirgil/COVID-press-conferences.git

\section{Acknowledgements}

We thank the Stockholm University library for its assistance and support, as well as the SweClarin Institutionen för Svenska Språket for their input on semantic issues. We received crucial feedback on earlier versions of this article from Richard Swedberg, the members of the Stockholm University Cultural Sociology Seminar and the Civil Sphere Theory Working Group. This research received no specific grant from any funding agency in the public, commercial, or not-for-profit sectors.

\section{References}

Alexander, Jeffrey C. 2010. The performance of politics: Obama's victory and the democratic struggle for power. Oxford University. 
Allcott, Hunt, Levi Boxell, Jacob Conway, Matthew Gentzkow, Michael Thaler, and David Yang. 2020. "Polarization and public health: Partisan differences in social distancing during the Coronavirus pandemic." Journal of Public Economics 191: 104254.

Ansell, Chris, Arjen Boin, and Paul 't Hart. 2014. "Political leadership in times of crisis." Pp. 419-38 in The Oxford handbook of political leadership, edited by R. A. W. Rhodes and Paul 't Hart. Oxford: Oxford University Press.

Bhatia, Aditi. 2006. "Critical Discourse Analysis of Political Press Conferences." Discourse \& Society 17(2): 173-203. http://www.jstor.org/stable/42889042.

Bligh, Michelle C., Jeffrey C. Kohles and James R. Meindl. 2004. "Charisma under Crisis: Presidential Leadership, Rhetoric, and Media Responses Before and After the September 11th Terrorist Attacks." Leadership Quarterly 15: 211-239.

Bligh, Michelle C., Jeffrey C. Kohles, and Rajnandini Pillai. 2005. "Crisis and charisma in the California recall election." Leadership 1(3): 323-52.

Bratman, Michael E. 1999. Faces of intention: Selected essays on intention and agency. Cambridge University Press.

Carroll, Matthew S., Lorie L. Higgins, Patricia J. Cohn and James Burchfield. 2006.

"Community wildfire events as a source of social conflict." Rural Sociology 71(2): 261-80.

Collins, Randall. 2004. "Rituals of solidarity and security in the wake of terrorist attack." Sociological theory 22(1): 53-87.

COVID-19 Data Repository by the Center for Systems Science and Engineering (CSSE) at Johns Hopkins University (JHU CSSE COVID-19 Data) https://github.com/CSSEGISandData/COVID-19.

Crayne, Matthew P., and Kelsey E. Medeiros. 2020. "Making sense of crisis: Charismatic, ideological, and pragmatic leadership in response to COVID-19." American Psychologist. Advance online publication. http://dx.doi.org/10.1037/amp0000715.

Cregan, Christina, Timothy Bartram, and Pauline Stanton. 2009. "Union organizing as a mobilizing strategy: The impact of social identity and transformational leadership on the collectivism of union members." British Journal of Industrial Relations 47(4): 701-22.

de Blasio, Emiliana, and Donatella Selva. 2020. "Affective Governance During the Covid-19 Crisis: Building Leadership, Trust, and Good Citizens." Tripodos 47(1): 67-85.

Dong, Ensheng, Hongru Du, and Lauren Gardner. 2020. “An interactive web-based 
dashboard to track COVID-19 in real time." The Lancet infectious diseases 20(5): 533-34. doi: 10.1016/S1473-3099(20)30120-1

Dwyer, Colin. 2020. "Andrew Cuomo To Receive International Emmy For 'Masterful' COVID-19 Briefings" NPR, November 21, https://www.npr.org/sections/coronavirus-liveupdates/2020/11/21/937445923/andrew-cuomo-to-receive-international-emmy-for-masterfulcovid-19-briefings?t=1643097706439.

Editor \& Publisher International Yearbook. 2000. New York: Editor \& Publisher.

Eshbaugh-Soha, Matthew. 2003. "Presidential Press Conferences over Time." American Journal of Political Science 47(2): 348-53.

Florio, Øystein, and Salvatore Linnebo. 2017. "Logic and Plurals." Pp. 451-63 in The Routledge handbook of collective intentionality, edited by Marija Jankovic and Kirk Ludwig. New York: Routledge.

Fischer, Kyle, Ananish Chaudhuri, and Quentin Atkinson. 2020. "Responses to the COVID-19 pandemic reflect the dual evolutionary foundations of political ideology." Retrieved May 28, 2021 (https://psyarxiv.com/qeap8).

Garnett, James L., and Alexander Kouzmin. 2007. "Communicating throughout Katrina: Competing and Complementary Conceptual Lenses on Crisis Communication." Public Administration Review 67(1): 171-88.

Gollust, Sarah E., Rebekah H. Nagler, and Erika Franklin Fowler. 2020. "The emergence of COVID-19 in the US: a public health and political communication crisis." Journal of Health Politics, Policy, and Law 45(6): 967-81.

Gonzalez, Stephen P., Jonathan N. Metzler, and Maria Newton. 2011. "The influence of a simulated 'pep talk' on athlete inspiration, situational motivation, and emotion." International Journal of Sports Science \& Coaching 6(3): 445-59.

Graham, Amanda, Francis T. Cullen, Justin T. Pickett, Cheryl Lero Jonson, Murat Haner, and Melissa M. Sloan. 2020. "Faith in Trump, Moral Foundations, and Social Distancing Defiance during the Coronavirus Pandemic." Socius 6: 2378023120956815.

Green, Jon, Jared Edgerton, Daniel Naftel, Kelsey Shoub, and Skyler J. Cranmer. 2020. "Elusive consensus: Polarization in elite communication on the COVID-19 pandemic." Science Advances 6(28), eabc2717.

Halverson, Stefanie K., Susan Elaine Murphy, and Ronald E. Riggio. 2004. "Charismatic 
leadership in crisis situations: A laboratory investigation of stress and crisis." Small Group Research 35(5): 495-514.

Hart, Roderick P., Sharon E. Jarvis, and Elvin T. Lim. 2002. "The American people in crisis: A content analysis." Political Psychology 23(3): 417-37.

Holmes, Bev J. 2008. "Communicating about emerging infectious disease: The importance of research." Health, Risk \& Society 10(4): 349-60.

Kern, Andrea, \& Henrike Moll. 2017. "On the transformative character of collective intentionality and the uniqueness of the human." Philosophical Psychology 30(3): 319-37.

Kirgil, Zeynep Melis, Rafael P. M. Wittek, and Tom Postmes. 2021. "Sustained cooperation in small groups." (Manuscript in preparation).

Lagerwerf, Luuk, Amber Boeynaems, Charlotte van Egmond-Brussee, and Christian Burgers. 2015. "Immediate attention for public speech: Differential effects of rhetorical schemes and valence framing in political radio speeches." Journal of Language and Social Psychology 34(3): 273-99.

Lyons, Joseph B., and Tamera R. Schneider. 2009. "The effects of leadership style on stress outcomes." The Leadership Quarterly 20(5): 737-48.

McClung, Jennifer Susan, Sarah Placì, Adrian Bangerter, Fabrice Clément, and Redouan Bshary. 2017. "The language of cooperation: shared intentionality drives variation in helping as a function of group membership." Proceedings of the Royal Society B: Biological Sciences 284(1863): 20171682.

Medeiros, Kelsey E., Matthew P. Crayne, Jennifer A. Griffith, Jay H. Hardy, Adam Damadzic. 2022. Leader sensemaking style in response to crisis: Consequences and insights from the COVID-19 pandemic. Personality and Individual Differences, 187, 111406.

Moreland, Amanda, et al. 2020. "Timing of state and territorial COVID-19 stay-at-home orders and changes in population movement - United States, March 1-May 31, 2020." Morbidity and Mortality Weekly Report 69(35): 1198.

Nelson, Laura K. 2020. "Computational grounded theory: A methodological framework." Sociological Methods \& Research 49(1): 3-42.

Nelson, Laura K. 2021. "Leveraging the alignment between machine learning and intersectionality: Using word embeddings to measure intersectional experiences of the nineteenth century US South." Poetics: 101539. 
Neiman, Jayme L., Frank J. Gonzalez, Kevin Wilkinson, Kevin B. Smith and John R. Hibbing. 2016. "Speaking different languages or reading from the same script? Word usage of Democratic and Republican politicians." Political Communication 33(2): 212-40.

NewsBank (2021) www.newsbank.com

Painter, Marcus, and Tian Qiu. 2020. "Political beliefs affect compliance with covid-19 social distancing orders." Available at SSRN 3569098.

Pennebaker, James W., Roger J. Booth, Ryan L. Boyd,and Martha E. Francis. 2015.

"Linguistic Inquiry and Word Count: LIWC2015." Austin, TX: Pennebaker Conglomerates (www.LIWC.net).

QSR International. 1999. "NVivo Qualitative Data Analysis Software, NVIVO 12." Available from https://www.qsrinternational.com/nvivo-qualitative-data-analysis-software/home/

Rakoczy, Hannes. 2017. "Development of collective intentionality." Pp. 407-19 in The Routledge handbook of collective intentionality, edited by Marija Jankovic and Kirk Ludwig. New York: Routledge.

RStudio Team. 2020. "RStudio: Integrated Development for R.” RStudio, PBC, Boston, MA http://www.rstudio.com/.

Ryan, John, and James Hawdon. 2008. "From individual to community: The "framing" of 4-16 and the display of social solidarity." Traumatology 14(1): 43-51.

Schäffner, Christina. 1997. Analysing political speeches. Philadelphia: Multilingual Matters.

Schweikard, David P. and Hans Bernhard Schmid. 2013. "Collective Intentionality." In The Stanford Encyclopedia of Philosophy, edited by Edward N. Zalta. Stanford, CA: Stanford University.

Searle, John. R. 1990. "Collective intentions and actions." Intentions in communication 401: 401.

Shamir, Boas, Michael B. Arthur, and Robert J. House. 1994. "The rhetoric of charismatic leadership: A theoretical extension, a case study, and implications for research." The Leadership Quarterly 5.1: 25-42.

Shepherd, Hana, Norah MacKendrick, and G. Cristina Mora. 2020. "Pandemic Politics: Political Worldviews and COVID-19 Beliefs and Practices in an Unsettled Time." Socius 6: $1-18$. 
Smith, Eric Alden. 2010. "Communication and collective action: language and the evolution of human cooperation." Evolution and human behavior 31(4): 231-45.

Stoltz, Dustin S., and Marshall A. Taylor. 2021. "Cultural cartography with word embeddings." Poetics: 101567.

Stroebe, Wolfgang et al. 2020. "The Political Dimension of COVID-19 Health-Protective Behavior in the United States." Retrieved May 28, 2020 (https://www.researchgate.net/profile/WolfgangStroebe/publication/345898707_Politics_and_COVID19_Health_Behaviors/links/5fb1385a299bf10c36809369/Politics-and-COVID-19-HealthBehaviors.pdf)

Taylor, Melanie, Beverley Raphael, Margo Barr, Kingsley Agho, Garry Stevens, and Louisa Jorm. 2009. "Public health measures during an anticipated influenza pandemic: factors influencing willingness to comply." Risk management and healthcare policy 2: 9.

't Hart, Paul and Arjen Boin. 2001. "Between crisis and normalcy: The long shadow of post-crisis politics.” Pp. 28-46 in Managing crises: Threats, dilemmas, opportunities, edited by Uriel R. Rosenthal, Arjen Boin, and Louise K. Comfort. Springfield, IL: Charles C. Thomas.

Titlestad, Kim N. 2019. Sustainable cooperation in small groups: dynamic interaction and the emergence of norms. [Groningen]: University of Groningen. https://doi.org/10.33612/diss.95433751

Tomasello, Michael and Hannes Rakoczy. 2003. "What makes human cognition unique? From individual to shared to collective intentionality." Mind \& language 18(2): 121-47.

Tomasello, Michael. 2014. A natural history of human thinking. Harvard University Press.

Tuomela, Raimo. 2013. Social ontology: Collective intentionality and group agents. Oxford University Press.

Turkel, Gerald. 2002. "Sudden solidarity and the rush to normalization: Toward an alternative

approach." Sociological Focus 35(1): 73-9.

Turner, Scott F., Laura B. Cardinal, and Richard M. Burton. 2017. "Research design for mixed methods: A triangulation-based framework and roadmap." Organizational Research Methods 20(2): 243-67. 
Villegas, Celso M. 2020. "Performing rituals of affliction: how a Governor's Press conferences provided mediatized sanctuary in Ohio." American Journal of Cultural Sociology 8(3): 352-83.

Warneken, Felix, Frances Chen, and Michael Tomasello. 2006. "Cooperative activities in young children and chimpanzees." Child development 77(3): 640-663.

Weick, Karl E., Kathleen M. Sutcliffe, and David Obstfeld. 2005. "Organizing and the process of sensemaking." Organization science 16.4: 409-421.

Wrenn, Marion C. 2012. "“Conflictinator": Media, metaphors, and citizen audiences." Poetics, 40(2), 200-216.

Zhang, Zhe, Ming Jia, and Lihong Gu. 2012. "Transformational leadership in crisis situations: evidence from the People's Republic of China." The International Journal of Human Resource Management, 23(19), 4085-109. 


\section{Author Biographies}

Zeynep Melis Kirgil is a PhD student in the Department of Sociology at Stockholm University. Her current research focuses on collective intentionality and cooperative behavior at different levels of analysis by using computational, quantitative and qualitative methodologies.

Andrea Voyer is an Associate Professor (docent and senior lecturer) in the Department of Sociology at Stockholm University. Her current research uses etiquette books as data in computational sociological and qualitative analyses of social inclusion and exclusion on the basis of immigration, race and class. 